\title{
COURSE REINVENTION GUIDE THROUGH REALISTIC MATHEMATICS EDUCATION TO IMPROVE GROUP CONCEPT UNDERSTANDING
}

\author{
Sunindri $^{1)}$, Sugiatno ${ }^{2)}$, Yulis Jamiah ${ }^{3)}$ \\ ${ }^{1)}$ Universitas Tanjungpura, Pontianak, Indonesia \\ E-mail: Sunindri.mtk@gmail.com \\ ${ }^{2)}$ Universitas Tanjungpura, Pontianak, Indonesia \\ E-mail: giatno66@gmail.com \\ 3) Universitas Tanjungpura, Pontianak, Indonesia \\ E-mail: yulis_jamiah@yahoo.co.id
}

\begin{abstract}
The preliminary study finds difficulty in group definition. Students have not had an understanding of the group definition concept. One alternative to give an understanding of the group definition concept is to develop reinvention guide to group definition. This research employs the realistic mathematics education learning approach to encourage and guide students to invent group definition concept. Therefore, this research aims at developing reinvention guide to group definition through realistic mathematics education to improve students understanding of group concept in FMIPA, UNTAN. The Research and Development (R \& D) method is employed in guide development. The subjects are five six-semester students with formal experience in learning abstract algebra, particularly group theory, and students with average in group module test and lowest score in fifth pre-test. The data analysis results indicate that students' group concept understanding is improved after receiving reinvention guide to group definition through realistic mathematics education based learning.
\end{abstract}

Keywords: Group concept understanding; Realistic mathematics education; Reinvention guide

\section{INTRODUCTION}

Experts in the National Research Council (NRC) (2001) state that it is important to learn about Algebra since it is used to anticipate students' adaptive reasoning and to support mathematical problem simplification. The document National Council of Teachers of Mathematics (NCTM) (2000) states that Algebra is one out of five standard contents of mathematics important to be studied that it supports the contents of mathematics and develops mathematical reasoning. According to Booker (2009), algebra plays an important role to solve problems of advanced mathematics, science, business, economics, trade, computation and other daily life problems. Therefore, mathematics students are required to understand algebra.

However, in fact, many students lack understanding of algebra concept, particularly group material, as indicated that they only memorize formulas, theorems and definitions, thus they find difficulty in answering problems developed in the form of analogy.

To identify the presumption, the researchers conduct an observation by giving problem in the form of rock-paperscissors game analogy with the answer is group definition. Sugiatno (2016) states that rock-paper-scissors game may be used to give analogy to raise an understanding of group definition. Based on the research, the researchers ask a question to three four-semester students of mathematics study program, FMIPA, UNTAN: Prove that rock-paperscissors game constitute group."

The results of observation conducted on 28 March indicate that no student is able to answer correctly. A student states that rock-paper-scissors game does not qualify one of axioms to state a set as group, which is associative, thus rock-paper-scissors game is not group. 
Two students state that rock-paper-scissors game does not meet associative characteristic, thus they conclude that rockpaper-scissors game is not group, without proving that such set has identity element and has inverse (Field note, 28 March).

Based on the three students' answers in the observation, we may assume that the students are not capable of developing the meaning of group definition despite the question clearly asking them to solve the problem through definition.

Sweden (2000) states that students will be considered as understanding definition meaning if they may generate definition from problems in daily life context. There is an indication that the problem exists since students are not able yet to understand the meaning contained in definitions in textbooks. Definitions in textbooks contain many terms given by mathematicians, of which meaning is not reached by students. This causes students state that it is difficult to study algebra. Similarly, lecturers state that they have not completely taught definition meaning to make students think about algebra, since the lecturers hardly find for transition from social arithmetical concept to algebra concept (NRC, 2001). The field phenomena constitute serious matter that needs solution.

Problem solving alternative may be viewed from two matters: how to learn and how to teach definition. One alternative to learn group definition is to re-find group definition. Moreover, the teaching alternative which must be conducted by lecturers is to teach by guiding students to employ their reasoning to invent group definition.

This is in line with the opinion of Findell (2001) that invention method "gives students a rich problem to explore. They will find patterns and relations, develop ideas and concepts, in creating objects and processes". In other words, through invention method, students are given chance to employ their reasoning and intuition to identify and "invent" structures from a mathematical concept. Further, experts in NCTM (2000) confirm it by stating that mathematics teaching must begin with something students know of and need.

Therefore, learning of group definition by using " invention method" and teaching of group definition begin with what students know of and need. To realize the concerned learning and teaching, the researchers choose rock-paper-scissors game to invent group definition. The reason that rock-paper-scissors game is used is to invent group definition, since there is similarity between algorithm in group concept and rock-paper-scissors game rule (Saputro, 2012).

Rock-paper-scissors game is a traditional game played by employing thumb, index finger and little finger. Rock-paperscissors game may be performed when two players simultaneously show their fingers, witnessed by both players. In line with Sugiatno's research (2016), rock-paper-scissors game may be represented to be "play group. The rock-paperscissors game results may be represented in the form of Pay off matrix (Turocy et al., 2001), appropriately stating group definition.
Therefore, it is necessary to make a guide to students' group definition reinvention and to lecturer's measures in group definition teaching. According to Cook's dissertation (2012), one guide to teach definition is guide to reinvention.

Guide to reinvention is a guide to teaching based on reinvention principle. According to Gravemeijer (2004), the reinvention principle is principle which give students chance to consider knowledge they obtain as their own knowledge, thus they will be responsible for their knowledge. This is appropriate to Frudenthal's opinion (2002) that guide to reinvention is a guide which help students reinvent definition. Therefore, guide to reinvention making aims at making students feel responsible for mathematics they have learned.

The designed guide to reinvention is a guide to reinvention of group definition. Guide to reinvention of group definition is made based on local instructional theory. According to the research conducted by Larsen (2013), designing instructional assignment centralized on group concept is a theory to support group definition reinvention. Gravemeijer (2004) also proposes that instructional design guides informal problem solving strategy and places students as the main owner of idea. Therefore, the guide to reinvention designing frame is based on local instructional theory.

Local instructional theory is instructional assignment sequence theory which becomes the main outcome of a project (Larsen, 2013). Instructional assignment focuses on building a model to be used in solving different algebraic structures (Cobb, 2000; Lockwood et al., 2013). Instructional assignment actively participates in learning activities which supports interaction in class.

Gravemeijer (2004) states that the effective way to teach definition appropriate to local instructional theory is teaching through Realistic Mathematics Education (RME). Its main purpose is to examine students' knowledge and students' process in understanding definitions (Cobb, 2000). This is certainly supported by mutual learning path, aiming at making students reinvent group definition and the teaching method applied to the guide to reinvention is appropriately performed with RME.

RME is an approach of mathematics education struggled for by Freudenthal $(1971,1973)$ to encourage the idea that "mathematics may and must be consistently self-learned through a person's mental activities" (Gravemeijer, 1999). RME suggests mathematics as human activities with concept in the form of real experience for students.

The main matter in RME is that students may obtain formal mathematics subject originated from informal mathematics. Panhizen (2000) also states that RME is one approach which bridges the teaching of informal mathematics towards formal mathematics.

According to Panhizen (2000), formal mathematics is mathematics stated in the form of mathematical notations and symbols, while informal mathematics is mathematics related to daily life. In this research, the researchers employ rock-paper-scissors game as a form of informal mathematics to bridge group definition reinvention, which is formal mathematics. 
Learning starting with daily life context in the form of rock-paper-scissors game may give students' brain stimuli to understand group definition. According to Frudenthal (2002), mathematics is human activity. In line with RME, which emphasizes on learning by reality and human daily activities, students are able to construct their own knowledge through direct experience. Therefore, learning which is conducted will be meaningful and able to improve students' group concept understanding.

Considering that algebra is important, the researchers are interested in conducting a research on developing guide to reinvention of group material through RME to improve students' concept understanding.

\section{RESEARCH METHOD}

This Research and Development ( $\mathrm{R} \& \mathrm{D})$ research is conducted to develop guide to reinvention. In the development, this research adapts to the research and development model of Plomp (2010) and Akker (2010).

The concerned subjects are five six-semester students of Mathematics Study Program, FMIPA, UNTAN with formal experience in learning abstract algebra, particularly group theory, and students with average score in group module test of abstract algebra subject and lowest score in the fifth pretest.

The designed instrument consists of two groups: (1) instrument in the form of learning media with RME in the form of guide to reinvention of group definition and students activity sheet (LAM); (2) learning outcome instrument in the form of pre-test and post-test.

The procedure to be performed consists of two stages: preparation and development. The measures which may be taken in the preparation stage and development stage of the research are:

\section{A. Preparation Stage}

This stage consists of initial investigation phase. The measures to be performed are conducting introductory study and literary study. The introductory study is conducted by investigating three students with respective scores A, B, and $\mathrm{C}$ in abstract algebra subject. The literary study is conducted by searching for literature to identify the cause and how to solve it.

\section{B. Development Stage}

This stage consists of three phases: (1) design phase; (2) realization or construction phase; and (3) final phase. Below are explanations of the measures in each phase.

The measures conducted in the design phase consist of: (1) arrange research instruments; (2) validate research instruments; (3) revise research instruments based on validation results.

The measures conducted in the realization and construction phase consist of: (1) conduct trial on research instruments; (2) revise research instruments based on the trial; (3) determine research subjects; (4) conduct pre-test; (5) teaching with guide to reinvention of group definition through RME; (6) conduct post-test; (7) distribute questionnaires for students' response to students; (8) conduct unstructured interview.

The measures conducted in the final phase consist of: (1) process and analyze the data; (2) conclude the research; (3) arrange research report.

\section{RESULT AND DISCUSSION}

\section{A. Result}

\section{1) Students' Concept Understanding before the Application of Guide to Reinvention of Group Definition}

One datum is obtained based on the research results: pretest (in the form of score ranging from 0-100) on 30 students' group concept understanding. The researchers also obtain students group module test score during course. The 30 students' pretest average score is 45.37 and their module test average score is 43 , thus the total average value is 44.22 . 15 students have score below the average, which means that $50 \%$ students are declared having no understanding of the group material.

\section{2) Measures Taken to Make Guide to Reinvention of Group Definition through $R M E$}

The measures to make guide to reinvention of group definition refer to Cook (2012). The instrument employed to reinvent group definition is rock-paper-scissors game referring to Sugiatno (2016).

The measures developed in the reinvention process of group definition include: (1) understand problems in daily life context. In this stage, the lecturer presents problems in daily life context, which is rock-paper-scissors game. Students are required to play rock-paper-scissors game and to analyze their game results. The rock-paper-scissors game understanding process is presented in the form of representation; (2) shift the problem to formal mathematical form. In this stage, the lecturer sets a condition to shift the representation form which has been understood by the students to formal mathematical form with other presentation in figure form. The students are indirectly, slowly guided to formal mathematical form. This aims at giving their mind space to understand mathematics; (3) bring out definition forming components or structures. In this stage, the lecturer asks the students question which may bring the students' answers out to invent the structure of group definition in consideration of students' psychological condition, of which thinking is still on the formal mathematical form. The questioning should be made after the lecturer ensures that the students are highly curious of and that they need the lecturer explanation. This condition may be formed by re-explaining the results of rock-paperscissors game; (4) arrange definition forming components or structures. In this stage, the lecturer filters the structures needed to form group definition. The lecturer reemphasizes the structures needed to state that a set with defined operation constitutes group. In constant consideration of students' preparedness to receive learning, the lecturer arranges the structure obtained and shows truth of each structure with systematic evidences; (5) reinvent definition. 
In this stage, the lecturer engages the students to make a summary and conclusion from the four structures found. The lecturer then expressly concludes that the four axioms systematically mentioned and shown are the group definition forming axioms, and expressly describes the group definitions obtained from the rock-paper-scissors game analogy. Finally, the lecturer concludes that the students are able to reinvent group definition.

\section{3) Students' Concept Understanding after the Application of Guide to Reinvention of Group Definition}

Based on the analysis on post-test results, the 30 students' post-test average score is 70.37 . This post-test score is the students' score after receiving learning with the application of guide to reinvention of group definition. The students' average score evidently increases with the difference between before and after receiving learning with guide to reinvention of group definition is 26.15 .

4) The Applicability of Guide to Reinvention of Group Definition through RME to Improve Students' Concept Understanding

According to the data analysis results of the applicability of guide to reinvention of group definition through RME filled by three observers, we may conclude that the measures in the guide to reinvention have been implemented $100 \%$. The applicability score of the guide to lecturer respective activity is 3.66 and the applicability score of the guide to respective activity is 3.53 . Therefore, the application of guide to reinvention of group definition through RME is classified as "very good" with total average of 3.595. This is supported with students' response questionnaire and unstructured interview.

\section{B. Discussion}

The results are pursuant to the objective of this research, which is to develop a guide to reinvention of group definition through RME to improve students' group concept understanding. Therefore, through this section, we shall propose some discussions related to this research objective in the form of explanation of students' group concept understanding before and after the application of guide to reinvention of group definition through RME, which is reviewed through pre-test and post-test answer results.

The indicators of concept understanding in this research are: (1) students are able to shift a form of representation to other form of representation in inventing group definition; (2) identification of objects based on whether or not the requirements for reinventing group definition are fulfilled; (3) recognition of various concept meanings and interpretations in inventing group definition.

The researchers provide 9 pre-test and post-test questions, with each indicator is represented by 3 questions. Questions number 1, 2, and 3 represent the first indicator, questions number 4, 5 and 6 represent the second indicator, and questions number 7, 8 and 9 represent the third indicator. After analysis on the questions by searching for the validity of questions, difficulty level, reliability and distinguishing factor, the question items number 1, 4 and 7 are evidently declared as valid for this discussion. The description of each question is discussed one by one pursuant to the question number as follows:

Question number 1 may measure students' ability to shift a form of representation to another form of representation from the rock-paper-scissors game concept to reinvent group definition. The question is asked to examine the following students' initial ability:

If Andi and Tomi play rock-paper-scissors game, there will be 3 possibilities arising from their play:

Possibility 1: Andi wins and Tomi is defeated;

Possibility 2: Andi is defeated and Tomi wins;

Possibility 3: a draw.

Arrange the representation of their play result in the form of table with win, defeated and draw categories and Andi serving as reference.

Before learning with guide to reinvention of group definition is given, the students find confusion in making table representation, since they are not given with opportunity to present their own representation in class learning process, but are required to follow what exemplified by lecturer. Another reason is that mathematics teaching method remains used to matter presentation, question sampling, and requesting students to answer practice questions, which thus do not allow students to optimally grow or develop their representation ability (Fitri, 2017). Therefore, the students find difficulty when they are asked to shift a form of representation to another form of representation.

After examining students' understanding of how they shift a form of representation, the researchers prepare learning which gives them opportunity to shift a form of representation to another form of representation. One learning method given to the students to solve such problem is to learn with guide to reinvention of group definition through RME.

In the learning process, the students are given opportunity to present their idea in expressing their representation. The presentation in the Students Activity Sheet (LAM) guide students to propose their thinking outcome of a form of representation. A post-test is conducted to measure their understanding.

After post-test is conducted, in which students' answers are analyzed, we may state that learning with guide to reinvention of group definition through RME improves students' group concept understanding.

This takes place because the guide to reinvention of group definition is specifically designed to create instruction to reinvent group definition. Larsen (2013) states that guide to reinvention is a guide specifically designed to create instruction in mathematics learning.

The guide to reinvention of group definition is taught through RME, which thus improve students' group concept understanding. Lestari and Surya (2017) state that students' concept understanding ability is higher if are taught with RME than if they receive learning topics using speech method. 
Pursuant to the indicator of group concept understanding in this research as measured with question number 1 , we may conclude that shifting a form of representation may open students' mind to reinvent group definition. Swinyard (2011) states that shifting a form of representation is a method which may engage students to actively reinvent definition. Therefore, the researchers present questions to shift a form of representation to another form of representation.

Question number 4 may measure students' ability to identify objects based on whether or not the requirements for group definition formation are fulfilled.

The question number 4 arranged based on students' group concept understanding indicator in the pre-test is as follows: A non-empty set is given,

$H=\left\{\left(\begin{array}{l}1 \\ 1 \\ 1\end{array}\right),\left(\begin{array}{l}-1 \\ -1 \\ -1\end{array}\right),\left(\begin{array}{l}0 \\ 0 \\ 0\end{array}\right)\right\}$. Show that $\mathrm{H}$ constitute group with an operation $\star$ which is defined as follows:

$$
\begin{aligned}
& \left(\begin{array}{l}
1 \\
1 \\
1
\end{array}\right) \star\left(\begin{array}{l}
1 \\
1 \\
1
\end{array}\right)=\left(\begin{array}{l}
-1 \\
-1 \\
-1
\end{array}\right) \\
& \left(\begin{array}{l}
-1 \\
-1 \\
-1
\end{array}\right) \star\left(\begin{array}{l}
-1 \\
-1 \\
-1
\end{array}\right)=\left(\begin{array}{l}
1 \\
1 \\
1
\end{array}\right) \\
& \left(\begin{array}{l}
0 \\
0 \\
0
\end{array}\right) \star\left(\begin{array}{l}
0 \\
0 \\
0
\end{array}\right)=\left(\begin{array}{l}
0 \\
0 \\
0
\end{array}\right) \\
& \left(\begin{array}{l}
1 \\
1 \\
1
\end{array}\right) \star\left(\begin{array}{l}
0 \\
0 \\
0
\end{array}\right)=\left(\begin{array}{l}
0 \\
0 \\
0
\end{array}\right) \star\left(\begin{array}{l}
1 \\
1 \\
1
\end{array}\right)=\left(\begin{array}{l}
1 \\
1 \\
1
\end{array}\right) \\
& \left(\begin{array}{l}
-1 \\
-1 \\
-1
\end{array}\right) \star\left(\begin{array}{l}
0 \\
0 \\
0
\end{array}\right)=\left(\begin{array}{l}
0 \\
0 \\
0
\end{array}\right) \star\left(\begin{array}{l}
-1 \\
-1 \\
-1
\end{array}\right)=\left(\begin{array}{l}
-1 \\
-1 \\
-1
\end{array}\right) \\
& \left(\begin{array}{l}
-1 \\
-1 \\
-1
\end{array}\right) \star\left(\begin{array}{l}
1 \\
1 \\
1
\end{array}\right)=\left(\begin{array}{l}
1 \\
1 \\
1
\end{array}\right) \star\left(\begin{array}{l}
-1 \\
-1 \\
-1
\end{array}\right)=\left(\begin{array}{l}
0 \\
0 \\
0
\end{array}\right)
\end{aligned}
$$

According to students' direct explanation, they are unable to answer question number 4 since they do not understand about group definition. Therefore, they are not able to identify objects which may or may not be fulfilled to form group definition, since the students are not used to obtain themselves objects which may or may not be fulfilled to form a definition.

Through this condition, the researchers prepare learning which will give the students opportunity to find by themselves group definition, by using guide to reinvention of group definition through RME. Learning with guide to reinvention is designed to enable students to find a group definition forming structure. Post-test questions are then given to measure their ability in understanding group definition after learning has been given.

According to the results of students' answer in the posttest, we may state that learning with guide to reinvention of group definition through RME may improve students' concept understanding. Therefore, the design of guide to reinvention of group definition and learning through RME may represent students' success in understanding group definition.

This is in line with the opinion of Gravemeijer (2008) that lecturer needs to help students, while ensuring that the students experience their learning as a mathematics 'creation' process. This way, we may state that the appropriateness to the researchers' objective in designing guide to reinvention is beneficial for students' mathematics " creation" process, particularly in group definition.

Furthermore, learning through RME with rock-paperscissors game may support students in determining whether or not an object is fulfilled in a requirement. Panhuizen (2003) states that the power of learning with RME is that it represents daily life context which is related to learning objective, to raise reasoning.

When students have the reasoning ability to transform a real condition to formal mathematical process, they may raise thinking which leads to fulfilled or unfulfilled objects in forming group definition. They will be able to master one indicator of concept understanding. Therefore, we may declare that they understand group definition based on the indicator of whether or not the requirements for an object are fulfilled.

The question number 7 may measure students' ability in recognizing group concept meaning and interpretation based on the analogy of rock-paper-scissors game. Pre-test question number 7 is as follows: Rizki and Tiwi play rockpaper-scissors game. In the first round, Rizki shows thumbs and Tiwi shows index finger. In the second round, Rizki shows index finger and Tiwi shows little finger. In the third round, Rizki shows little finger and Tiwi shows thumb. Who wins this rock-paper-scissors game?

According to the interview, the students have their answer empty because of the following matters: (1) they do not know the rule of rock-paper-scissors game; (2) they find it difficult to understand the problem of question and run out of time.

After learning with guide to reinvention of group definition through RME has been given, post-test is conducted. According to students' answers in the post-test, we may conclude that they are able to answer the question number 7 of post-test since they get used to give interpretation and meaning to a concept. This takes place since learning process based on guide to reinvention of group definition lead students to give interpretation and meaning.

Gravemaijer (2008) states that guide to reinvention may investigate students' informal interpretation and solution, which may thus anticipate more formal mathematical practice. Therefore, informal reasoning is used in definition finding process.

In this research, the researchers employ any interpretation and meaning contained in rock-paper-scissors game as an alternative to reinvent group definition. Rock-paper-scissors game is also made a basis to open students' mind to reason in definition reinvention. This explains that students have an understanding of group definition. 


\section{CONCLUSION AND SUGGESTIONS}

\section{A. Conclusion}

According to the data analysis results, we may conclude that: (1) students' group concept understanding before the application of guide to reinvention of group definition through RME based on pre-test average score and average score of group module test of abstract algebra subject is 44,22 ; (2) the measures in making the guide to reinvention of group definition through RME to improve students' group concept understanding are: understand problems in daily life context, shift the problem to formal mathematical form, bring out definition forming components or structures, arrange definition forming components or structures, and reinvent definition; (3) students' group concept understanding after the application of guide to reinvention of group definition through RME based on post-test average score is 70.37 ; (4) the applicability of guide to reinvention of group definition with the measures from the guide to reinvention is classified as "very good" with total average 3.595. In addition, the applicability of guide to reinvention is also reviewed through questionnaire of students' response and unstructured interview.

\section{B. Suggestion}

According to the conclusion and research results, we hereby propose the following suggestions: (1) the measures in the guide to reinvention of group definition may be employed to reinvent other definitions. However, we have to search for appropriate analogy in daily life context as an instrument to reinvent definition; and (2) this research may be continued further and it would be more interesting to provide further problem solving to disclose other concept invention in mathematics. This can be conducted through the set formed based on the category of rock-paper-scissors game outcome.

\section{REFERENCES}

Akker, J.V. (2010). Curriculum Desain Research. Proc. the seminar conducted at the East China Normal University, 2010, paper 2, p. 37.

Booker, G. (2009). Algebraic Thinking: Generalising Number and Geometry to Express Patterns and Properties Succinctly.

Cobb, P. (2000). Conducting Teaching Experiments in Collaboration with Teachers. In A. Kelly \& R. Lesh (Eds.). Handbook of Research Design in Mathematics and Science Education, Mahwah, NJ: Erlbaum, 307334.

Cook. J.P. (2012). A Guided Reinvention of Ring, Integral Domain, and Field. Dr. Eng. Dissertation. The Graduate Faculty, Norman, Oklahoma.

Findell, B. (2001). Learning and Understanding in Abstract Algebra. Doctoral Dissertation, The University of New Hampshire. Unpublished.
Fitri et al. (2017). Meningkatkan Kemampuan Representasi Matematis Melalui Penerapan Model Problem Based Learning. Jurnal Dedaktik Matematika, 4, 59-67.

Frudenthal, Hans. (2002). Revisiting Mathematics Education. London: Kluwer Academic Publishers.

Gravemeijer, K. (1999). How Emergent Models May Foster The Constitution of Formal Mathematics. Jurnal Mathematical Thinking and Learning, 2, 155-177.

Gravemeijer, K. (2008)." RME Theory and Mathematics Teacher Education. Tools and Processes in Mathematics Teacher Education, 6, 283-302.

Gravemeijer. K. (2004). Learning Trajectories and Local Instruction Theories as Means of Support for Teachers in Reform Mathematics Education. Jurnal Mathematical Thinking and Learning, 6, 105-128.

Larsen, S. (2013). A Local Instructional Theory for The Guided Reinvention of The Group and Isomorphism Concepts. Journal of Mathematical Behavior, 32, 712725.

Lestari, L. and Surya, E. (2017). The Effectiveness of Realistic Mathematics Education Approach on Ability of Students' Mathematical Concept Understanding. International Journal of Sciences: Basic and Applied Research (IJSBAR), 34, 91-100.

Lockwood, E., Johnson, E., and Larsen, S. (2013). Developing Instructor Support Materials for Aninquiry-Oriented Curriculum. Journal of Mathematical Behavior, 32, 776-790.

National Council of Teachers of Mathematics. (2000). Principles and Standards for School Mathematics. USE: Trademark of Key Curriculum Press.

National Research Concil. (2001). Adding It Up: Helping Children Learn Mathematics. Washington DC: National Academy Press.

Panhuizen, M. (2000). Mathematics Education in The Netherlands: A Guided Tour. Freudenthal Institute Cdrom for ICME9, Utrecht: Utrecht University.

Panhuizen, M. (2003).“ The Didactical Use of Models in Realistic Mathematics Education: An Example from A Longitudinal Trajectory on Percentage. Kluwer Academic Publishers, 54, 9-35.

Plom, T. (2010). Educational Desaign Research: An Introduction. Proc. the seminar conducted at the East China Normal University, 2010, paper 1, p. 9.

Saputro, B.A. (2012). Grup Permutasi Siklis dalam Permainan Suit. Jurnal Ilmiah Program Studi Matematika STKIP, 1, 153-158.

Sugiatno. (2016).“Permainan "Sut" Membentuk Grup Dolanan. Jurnal Pendidikan Matematika, Universitas Tanjungpura.

Sweden. (2000). Fundemental of Teaching Mathematics at University Level. Imperial Collage Press.

Swinyard, C. (2011). Reinventing The Formal Definition of Limit: The Case of Amy and Mike. Journal of Mathematical Behavior, 30, 93-114.

Turocy., Theodore, L., and Stengel, Bernhard V. (2001). Game Theory, CDAM Research Report LSE-CDAM. 